\title{
A eNfermagem e A CriançA *
}

\author{
** Dulce Neves da Rocha
}

$\operatorname{RBEn} / 01$

ROCHA, D.N. - A enfermagem e a criança. Rev. Bras. Enf,; DF, 32 : 245-250, 1979.

- Evolução Histórica da Assistência à Criança

A atenção dispensada à criança tem sido moäificada através dos tempos, por influências de ordem religiosa, tradiçöes culturais, fatores econômicos e sociais.

Nas tribos primitivas a criança era bem aceita, já que uma prole numerosa proporcionava maior prestígio durante a vida, maior força de trabalho para a família e, nos grupos mais religiosos, assegurava wais oraçōes após a morte. Em período de crise econômica, no entanto, o infanticídio era praticado com naturalidade.

Uma rápida consulta aos primeiros documentos de História Geral verificamos que os Caldeus já nos séculos XX e XXI A.C., incluíam no Código Hamurabi prescriçōes de proteção às gestantes e amparo aos órfãos. Os Inảus, no Rig-Veda, destinavam um capítulo do volume Jahir-Veda à higiene da criança, desde o nascimento, e as irregularidades durante a lactação; o Código Ma- nu também apresenta conselhos sobre Higiene Infantil. Pasteriormente, no Papiro de Ebers, os egípcios determinavam medidas de amparo às famílias e à criação dos filhos, bem como estimulavam o aleitamento materno; o Antigo Testamento nos traz várias recomendações sobre cuidados à gestante e valorização dos filhos, que eram considerados uma bênção do céu e sua falta na família correspondia a uma maldição.

A civilização Greco-Romana revela uma decadência nos cuidados dispensados à criança, resultante da dissolução da família, causada pela degradação moral da Sociedade.

Em Roma as crianças eram sacrificadas para satisfazer reis e atender a deuses. A História registra rituais de banhos de sangue quente de criança para homenagear reis; imolaçōes de crianças para abrandar a cólera dos deuses; o massacre decretado por Herodes; os gregos selecionavam as crianças vigorosas e perfeitas fisicamente, eliminando as que apresentavam defeitos ou fragilidade.

* Conferência proferida na sessáo de abertura da Semana de Enfermagem — Rio - 1979.

* Docente da Escola de Enfermagem Ana Néri - UFRJ. 
ROCHA, D.N. - A enfermagem e a criança. Rev. Bras. Enf,; DF, 32 : 245-250, 1979.

Só no tempo de Augusto, surgiram em Roma lejs de proteção à criança e respeito às mães. O Imperador Nerva, posteriorinent:, preocupou-se com a fome das crianças abandonadas e determinou que o Estado se encarregasse de alimentá-las. Esse trabalho foi prosseguido por Trajano, que chegou a alimentar 5.000 meninos. Alguns outros imperadores preocuparam-se com a sorte das crianças, entre eles Antônio Pio, Marco Aurélio, Séptimo Severo e Justiniano.

\section{- A Criança na Idade Média}

No início da era Cristã, médicos, pessoas caridosas e homens do governo preocupavam-se com a sorte das crianças, que, quando abandonadas, eram escravizadas por aqueles que as encontrassem. Instituiçōes religiosas foram criadas com o objetivo de recolher essas crianças. $O$ primeiro asilo destinado a abrigar menores abandonados foi fundado pelo bispo de Milão no ano 787 . Em Roma surgiram outros, mas a mortalidade das crianças recolhidas excedia algumas vezes a $90 \%$.

U m milênio mais tarde (1870), São Vicente de Paulo desenvolveu instituições assistenciais e, graças a seu prestígio, foi decretada na França, uma lei atribuindo ao Estado a responsabilidade pela assistência ao menor abandonado. Em 1874 o Senador Roussell, que era médico, alarmado com a alta mortalidade infantil, conseguiu a aprovação da "Lei Roussell", que tratava da Proteção da criança na Primeira Infância, e outras medidas de assistência ao menor. Outros países seguiram o exemplo da França.

\section{- $1 .^{a}$ S Leis sobre o Trabalho da Mulher}

Até à época da Revolução Industrial, embora nas camadas mais pobres da população houvesse carência econômica, havia possibilidade de atendimento às necessidades afetivas e sociais da criança no sistema de vida em que a mulher era ocupada apenas dos afazeres domésticos e cuidados com os filhos. A utilização da mão-de-obra feminina e da própria criança precocemente nas fábricas provocou radical transformação na vida familiar.

Tornou-se então indispensável a interferência dos Governos, elaborando leis que regulassem o trabalho da mulher e do menor tendo em vista assegurar à criança condições de se desenvolver satisfatoriamente.

Na Suíça em 1877 surge a primeira lei regulamentando o trabalho feminino na indústria, afastando do trabalho a mulher no período perinatal. Posteriormente foram proibidas algumas atividades à gestante. A Inglaterra promulgou sua primeira Lei Trabalhista em 1901. (1)

No entanto a primeira proposta de lei regulando o trabalho da mulher ocorreu aqui no Brasil, pois em 1819, José Bonifácio propunha à Assembléia Constituinte a seguinte emenda:

"A escrava durante a prenhez e pas-
sado o terceiro mês não será força-
da a trabalhos violentos e aturados.
No oitavo mês será ocupada somen-
te da casa, depois do parto terá um
mês de convalescença e, passado,
este, durante um ano não trabalha-
rá longe da Cria."

- Expansão da Assistência à Criança

No século XVII o índice de mortalidade infantil atingia a cifra de $\mathbf{5 0 0}$ por 1.000. Ao final do século XIX caía para 200, taxa ainda alarmante.

Até 1930 eram raros os estudos sobre o desenvolvimento infantil e as necessidades da criança. A partir de então a Medicina, a Nutrologia, a Psicologia e a Pediatria foram abrindo caminhos para a investigação no campo do desenvolvimento humano e modificando os critérios para a assistência infantil. A maioria dos governos aceitou o princípio de que o futuro da pátria repousa 
ROCHA, D.N. - A enfermagem e a criança. Rev. Bras. Enf,; DF, 32 : 245-250, 1979.

no tipo de assistência prestada ao ser humano desde o início de sua formação.

Numa tentativa de propiciar melhor assistência às crianças de todo o mundo foram proclamados em Genebra, em 1924, os Direitos da Criança, cuja aprovação pelas Naçōes Unidas foi feita por unanimidade em 1959. Porém esses äireitos não passam até hoje, de mera figura de retórica para uma grande parte de crianças de nossa época.

Ao comemorar-se o vigésimo aniversário da Declaração pode-se constatar que imensa população de crianças no nuundo inteiro, com concentração maior em algumas regiōes, não recebe os cuidados minimos para permitir o desenvolvimento de seu potencial biológico.

\section{- Tendências Atuais da Assistência Infantil}

Com as medidas sanitárias e sócioeconômicas adotadas em alguns países, a mortalidade infantil atinge hoje niveis extremamente baixos (10\%), enquanto outros ostentam a mesma taxa observada na Europa ao final do século passado (200\%). (2)

Publicaçōes da Organização Mundial de Saúde revelam que cerca de $500 \mathrm{mi}$ lhōes de pessoas, em sua maioria crianças, sofrem de desnutrição e suas conseqüências. $O$ estado de nutrição da mãe reflete-se no peso do feto ao final da gestação. Enquanto nos países desenvolvidos é minimo o número de crianças nascidas com peso inferior a $2.500 \mathrm{~g}$, em alguns outros essa cifra atinge de 20 a $30 \%$. (2)

Os programas assistenciais fundamentam-se nas necessidades em termos de saúde, porém os instrumentos comumente utilizados para avaliar essas necessidades são os indicadores de morbimortalidade. Mais recentemente vem senco dada importância a informaçōes relativas ao crescimento e desenvolvimento, bem como à higiene da reprodução, como indicadores de saúde. Pela análise dessas informaçōes é possivel identificar os problemas principais que afetam a saúde e determinar o tipo de assistência, de acordo com os critérios de prioridade adotados.

A assistência infantil, como os demais setores assistenciais não pode ser analisada nem acionada de modo isa lado, já que a saúde da criança é influenciada por fatores extra-setoriais. O estado de saúde da criança numa comunidade, reflete sua situação sócioeconômica, educacional e cultural, bem como suas condiçōes de habitação e saneamento ambiental.

Para atender às necessidades da criança torna-se portanto indispensável planejar açōes de saúde orientadas para a familia, levando em conta seus valores, tradiçōes, crenças, religiōes, hábitos e aspiraçōes. E ainda necessário identificar o grau de influência desses fatores sobre o desenvolvimento humano, principalmente em suas fases de maior vulnerabilidade, representadas pelos periodos pré-natal e durante a infância. Torna-se óbvio portanto que os programas de assistência à infância devem no minimo abranger toda a população materno-infantil, que no Brasil é representada por mais de $70 \%$ da população. (3)

Um comitê de peritos da OMS, em Saúde Materno-Infantil considerou que os programas assistenciais destinados a esse grupo devem englobar desde a solução dos problemas sanitários que afetam de forma imediata a mãe e a criança até aspectos relacionados com a saúde do indivíduo durante toda a vida e com a saúde da coletividade. Mediante suas atividades em benefício do desenvolvimento infantil e de educação sanitária de pais e filhos; esses serviços procuram como objetivo um estado de saúde de todos os individuos, durante toda a vida. $O$ efeito dos cuidados maternos minuciosos e bem orientados sobre a saúde da familia e da coletividade são importantes fatores para o desenvolvi- 
ROCHA, D.N. - A enfermagem e a criança. Rev. Bras. Enf,; DF, 32 : 245-250, 1979.

mento do indivíduo, do grupo social e da nação. (4)

No Brasil, o grupo materno-infantil tem sido objeto de prioridade do Governo, pois representa parcela ponderável da população e apresenta características de alta vulnerabilidade.

Alguns indicadores de Saúde podem evidenciar as condições de saúde dessa população. A média de mortalidade infantil em capitais brasileiras situa-se em torno de $90 \%$, com variações de 40,2 em Aracaju e 256,4 em Recife. (3) A grande maioria das causas desses óbitos no entanto, pertence à classe das doenças evitáveis e influenciadas por fatores sócio-econômicos e, principalmente, pelas condições de saneamento básico. Os distúrbios digestivos, estão diretamente subordinados à disponibilidade de água potável e serviços adequados de remoção de dejetos.

Em 1974 apenas 65,0\% da população urbana brasileira dispunha de serviços de abastecimento de água e $29 \%$ de serviços de esgotos. O quadro acima nos mostra o aumento alcançado em 1976 e o previsto para 1979 pelo II Plano Nacional de Desenvolvimento. (5) Notase porém grande parcela da população urbana ainda vive sem condições mínimas de higiene habitacional.

Nos países desenvolvidos a mortalidade infantil desceu progressivamente à níveis muito baixos, limitando-se à mortalidade neonatal, cujas causas não estão diretamente ligadas a fatores ambientais. Na Suécia, por exemplo a mortalidade neo-natal está concentrada praticamente na primeira semana de vida, sendo ainda mais elevada nas primeiras 24 horas. (7)

No Brasil os recursos assistenciais além de sobrecarregados por fatores extra-setoriais são ainda agravados pela falta de coordenação das institucionais produtoras de bens e serviços que atuam na área de saúde. (3)

Levantamentos feitos pelo Ministério da Saúde têm revelado que os recur- sos humanos para a assistência à mulher e à criança são também insatisfatórios, uma vez que é insuficiente o número de médicos especializados em relação ao grupo materno-infantil, e que se observa uma inversão da proporção médico/enfermeiro, que é aproximadamente $6: 1$.

Cabe ainda ressaltar que a falta de infra-estrutura dos serviços de saúde contribui de modo intenso para agravar a insuficiência quantitativa de recursos humanos, por determinar inadequada distribuição e sub-utilização dos mesmos. Atividades de grande responsabilidade técnica são freqüentemente delegadas a profissionais despreparados enquanto os profissionais de maior qualificação se ocupam de tarefas burocráticas ou que podem e devem ser atribuídas a outros profissionais.

Quanto à assistência especifica à criança, além da insuficiência numérica e sub-utilização de enfermeiros, cabe ressaltar a falta de estudos adicionais ao Curso de Graduação em Enfermagem para permitir um preparo mais profundo nos problemas relacionados à infância, suas necessidades prioritárias, as fatores de equilíbrio da saúde da criança e os recursos assistenciais que podem ser utilizados para maior eficácia das ações de enfermagem.

O Conselho Federal de Eclucação ao reformar o Currículo de Enfermagem em 1972, (8) determinou que o Curso de Enfermagem seja realizado em três partes sucessivas a saber:

a) Período Pré-Profissional;

b) Tronco Profissional Comum, levando à graduação do enfermeiro e habilitando-o a acesso à parte seguinte;

c) Habilitações, conduzindo pelas seleções de matérias adequadas, à formação do enfermeiro Médico-Cirúrgico, ảe Enfermeira Obstétrica e do Enfermeiro de Saúde Pública, respectivamente a partir do enfermeiro. 
ROCHA, D.N. - A enfermagem e a criança. Rev. Bras. Enf,; DF, 32 : 245-250, 1979.

Não existe portanto amparo legal para Habilitação em Enfermagem $\mathrm{Pe}$ diátrica. A formação do enfermeiro na área pediátrica restringe-se, ao ensino ministrado no Tronco Profissional Comum, cuja carga horária varia de uma para outra Escola, de 160 a 250 horas de atividades teórico-práticas. (*) Os poucos cursos existentes no Brasil a nível de Pós-Graduação na área pediátrica (dois em São Paulo e um em Porto Alegre) não chegaram ainda a capacitar 200 profissionais para o ensino e melhorar a assistência à criança.

\section{ATIVIDADES DE ENFERMAGEM NOS PROGRAMAS DE ASSISTENCIA PEDIÁTRICA}

\section{- Ações Preventivas}

São cada vez mais abrangentes as funçōes da enfermagem na assistência à criança. As açōes preventivas assumem importância crescente, dirigindo-se para o grupo familiar, com ênfase especial para as gestantes que devem receber orientação sobre a prevenção de fatores de risco para o feto, estímulo ao aleitamento natural, bem como os cuidados necessários para assegurar ambiente propício a criança durante a fase inicial da vida extra-uterina.

A insuficiência quantitativa de enfermeiros pode ser compensada quando se estabelece um sistema de trabalho que propicia o aproveitamento integral do potencial de trabalho do enfermeiro. Isso se tem alcançado quando é bem desenvolvido e implementado o conceito de trabalho em equipe, tornando possísivel a delegação de funçōes ao pessoal auxiliar, encarregando cada categoria profissional de atividades compatíveis com seu preparo.

Essa delegação de funçōes permite abranger uma parcela bem maior da população com um reduzido número de enfermeiros, aos quais cabe a responsabi- lidade de planejar atividades, definir as açōes a serem desenvolvidas, treinar o pessoal auxiliar, analisar e avaliar os procedimentos realizados.

$O$ rendimento do trabalho pode ser ainda ampliado pela participação de grupos da comunidade, principalmente aqueles vinculados à área da educação.

Considerando ainda que o periodo de maior vulnerabilidade do ser humano, situa-se na fase pré-natal e inicio da vida pós-natal, faz-se mister assegurar as melhores condiçōes de assistência durante esses períodos. Segundo os dados apresentados no Anuário Estatístico do IBGE, referentes ao ano de 1976, (9) a ocorrência de partos em domicílio é ainda bastante elevada, pois para um total de 5.744.307 nascimentos registrados em 1976, apenas 1.639 .960 partos ocorreram nos hospitais próprios e contratados pelo INPS e pelo FUNRURAL.

Parece-nos pouco provável que seja significativo o número de partos hospitalares fora da assistência previdenciária, e isso nos leva a crer que outra medida, relevante dentro da nossa realidade sanitária é o treinamento e controle de curiosas, medida aliás recomendada pelo Ministério da Saúde.

A curiosa exercendo grande influência sobre a população rural e da periferia humana, quando treinada, orientada e controlada, presta inestimável contribuição para propiciar condiçōes de saúde à mãe e à criança.

- Ações Curativas

Na evolução histórica da assistência à criança observa-se que os primeiros progressos da pediatria médica, despertou a necessidade de capacitar pessoal de enfermagem para formar o núcleo inicial do que se pode hoje denominar "equipe pediátrica". O primeiro hospital infantil de que se tem notícia foi aberto em Paris em 1802. Dava-se o pri-

- Levantamento realizado em abril de 1979 em 44 Escolas de Enfermagem. 
ROCHA, D.N. - A enfermagem e a criança. Rev. Bras. Enf,; DF, 32: 245-250, 1979.

meiro passo para permitir à criança doente um tratamento que melhor atendesse as suas necessidades como ser em rapıdo desenvolvimento. A Enfermagem porém ainda nāo existia como ciência, o que só veso a acontecer mais de meio século depois. $\mathrm{Em} 1870$ era nomeado o 1. Professor de Pediatria nos Estados Unidos; oito anos depois fundava-se a Sociedacle Estadunidense de Pediatria e a Universidade de Harvard criava um Departamento de Pediatria. No ano seguinte (1889) na mesma Universidade surgia uma Escola de Enfermagem. Parece não haver dúvidas, que a assistência pediátrica é inexeqüivel divorciada de um sentido de trabalho de equipe, face ao grau de dependência do paciente e, principalmente, pela caracteristica tão bem definida por Alcântara quando diz que a peculiaridade da Assistência Pediátrica é ser evolutiva. As mudanças de comportamento e de necessidades da criança ocorrem em ritmo acelerado exigindo tomadas de decisōes que só podem ser efetuadas por profissionais preparados para compreender e atender à criança. E o enfermeiro, como lider da equipe encarregada de assistir, 24 horas por dia a criança doente, portanto em situação de crise, geralmente agravada pela separação dos pais e do ambiente familiar, deve ser adequadamente preparado para exercer essa função. Nas açōes curativas a enfermagem, além de responsabilizar-se pelo atendimento às necessidades básicas da criança, tem atuação marcante nas medidas que levam ao diagnóstico do quadro pa- tológico, no plano terapêutico e nas atividades de reabilitação.

Finalizando, lembramos uma passagem da vida de São Vicente de Paulo. Graças aos seus trabalhos, em benefício dos doentes e das crianças desamparadas, ele era freqüentemente cercado por pessoas importantes, e, em certa ocasiāo estava com um grupo de Damas da Sociedade que demonstravam pretensōes filantrópicas e grande apreensão com a sorte das crianças abandonadas na França, quando ouviram um choro de criança. Era mais uma deixada à sua porta. Ele tomou a criança nos braços e, dirigindo-se às senhoras presentes, perguntou quem poderia encarregar-se de cuidá-la, já que ele, sendo homem, não tinha bastante habilidade para essa tarefa. Uma a uma, cada senhora apresentou de imediato uma justificativa convincente para eximir-se do encargo. Sentindo a inutilidade das "boas intençōes", São Vicente procurou uma senhora pobre, já com vários filhos para criar, e entregou-lhe mais um.

Cabe-me agora deixar apenas duas das questōes que nos afligem como educadores e como profissionais de Saúde.

- Estão nossas Escolas capacitando enfermeiros para atender as necessidades atuais da criança brasileira?

- Estamos, cada um de nós desenvolvendo as açōes que estão a nasso alcance para proporcionar melhores condiçōes de vida à criança e ao jovem de hoje?

\section{REFERENCIAS BIBLIOGRAFICAS}

1. MARTAGAO - Puericultura.

2. O CORREIO DA UNESCO - Ed. Braleira. Rio de Janeiro, Fundação Getúlio Vargas, 7(3), março, 1979.

3. M.S. - Programa de Saúde MaternoInfantil - 7975.

4. OPAS/OMS - Série de Informes Técnicos, n. $.^{\circ 28}, 1969$, pág. 5.

5. F. IBGE. - Pesquisa Nacional por Amostra de Domicilios - 1976.
6. II Plano Nacional de Desenvolvimento - (1975-1975).

7. OPAS/OMS - Nuevas Tendências y Métodos de Assistência Materno-Infantil en los servicios de Salud. Série de Informes Técnicos 600, Genebra, 1976.

8. BRASIL - Ministério da Educaçāo e Cultura - CFE. Parecer 163/72 aprovado em 28-1-72.

9. F. IBGE - Anuário Estatístico - 1977. 